\title{
A Neocortical Delta Rhythm Facilitates Reciprocal Interlaminar Interactions via Nested Theta Rhythms
}

\author{
Lucy M. Carracedo, ${ }^{1}$ Henrik Kjeldsen, ${ }^{1}$ Leonie Cunnington, ${ }^{1}$ Alastair Jenkins, ${ }^{2}$ Ian Schofield, ${ }^{3}$ Mark 0. Cunningham, ${ }^{1}$ \\ Ceri H. Davies, ${ }^{4}$ Roger D. Traub, ${ }^{5,6}$ and Miles A. Whittington ${ }^{7}$ \\ ${ }^{1}$ Institute of Neuroscience, The Medical School, Newcastle University, Newcastle upon Tyne, NE2 4HH, United Kingdom, Departments of ${ }^{2}$ Neurosurgery \\ and ${ }^{3}$ Clinical Neurophysiology, Royal Victoria Infirmary, Newcastle upon Tyne NE1 4LP, United Kingdom, ${ }^{4}$ GlaxoSmithKline Neural Pathways Discovery \\ Performance Unit, Research and Development China, Biopolis, Singapore, ${ }^{5}$ Department of Physical Sciences, IBM T. J. Watson Research Center, New York, \\ New York 10598, ${ }^{\circ}$ Department of Neurology, Columbia University, New York, New York 10032, and 7Hull York Medical School, University of York, York \\ Y010 5DD, United Kingdom
}

Delta oscillations $(1-4 \mathrm{~Hz})$ associate with deep sleep and are implicated in memory consolidation and replay of cortical responses elicited during wake states. A potent local generator has been characterized in thalamus, and local generators in neocortex have been suggested. Here we demonstrate that isolated rat neocortex generates delta rhythms in conditions mimicking the neuromodulatory state during deep sleep (low cholinergic and dopaminergic tone). The rhythm originated in an NMDA receptor-driven network of intrinsic bursting (IB) neurons in layer 5 , activating a source of $\mathrm{GABA}_{\mathrm{B}}$ receptor-mediated inhibition. In contrast, regular spiking (RS) neurons in layer 5 generated theta-frequency outputs. In layer $2 / 3$ principal cells, outputs from IB cells associated with IPSPs, whereas those from layer 5 RS neurons related to nested bursts of theta-frequency EPSPs. Both interlaminar spike and field correlations revealed a sequence of events whereby sparse spiking in layer $2 / 3$ was partially reflected back from layer 5 on each delta period. We suggest that these reciprocal, interlaminar interactions may represent a "Helmholtz machine"-like process to control synaptic rescaling during deep sleep.

\section{Introduction}

Delta rhythms $(1-4 \mathrm{~Hz})$ are associated with deep sleep non-rapid eye movement stages NREM3 and 4 . These sleep stages are manifest during the first few hours of sleep in humans and are linked to the consolidation of memories of conscious events (Huber et al., 2004). However, it remains unclear how such memory consolidation may take place and even what the mechanistic origin of the delta rhythm may be.

Although much is known about the local origins of slow-wave oscillations ( $<1 \mathrm{~Hz})$ in neocortex (Compte et al., 2003; Shu et al., 2003; Hasenstaub et al., 2005; Haider et al., 2006) and thalamus (Crunelli and Hughes, 2010), relatively little is yet known about cortical delta rhythms in the $1-4 \mathrm{~Hz}$ band. A thalamic generator of delta rhythms (1-4 Hz), modified by sensory input, is seen in thalamus (Amzica et al., 1992), and specific neuronal mechanisms involving behavior of intrinsic membrane conductances

\footnotetext{
Received Feb. 18, 2013; revised May 14, 2013; accepted May 17, 2013.

Author contributions: M.A.W. designed research; L.M.C., L.C., M.O.C., and M.A.W. performed research; A.J. and I.S. contributed unpublished reagents/analytic tools; H.K., C.H.D., R.D.T., and M.A.W. analyzed data; M.A.W. wrote the paper.

This work was supported by the Wellcome Trust and the Wolfson Foundation. R.D.T. was supported by IBM National Institutes of Health/National Institute of Neurological Disorders and Stroke Grant R01NS044133, and the Einstein Stifftung Berlin.

The authors declare no competing financial interests.

This article is freely available online through the J Neurosci Author Open Choice option.

Correspondence should be addressed to Miles A. Whittington, Hull York Medical School, Biology F1, York Univer-

sity, Heslington Y010 5DD, UK. E-mail: miles.whittington@hyms.ac.uk.

L. M. Carracedo's present address: Lilly UK, Erl Wood Manor, Windlesham, Surrey, GU20 6PH, UK.

DOI:10.1523/JNEUROSCI.0735-13.2013

Copyright $\odot 2013$ the authors $\quad 0270-6474 / 13 / 3310750-12 \$ 15.00 / 0$
}

$\left(I_{\mathrm{h}}\right.$ and $I_{\mathrm{T}}$ ) has been well characterized (Pirchio et al., 1997; Hughes et al., 1999, 2002). Although such a mechanism, given the density of thalamocortical projections, could readily account for a cortical analog as simply an imposed rhythm, some forms of delta rhythm have characteristics suggesting a purely cortical origin (Amzica and Steriade, 1998, Fell et al., 2002). In addition, during sleep it has been suggested that cortical delta rhythms can be generated locally in a use-dependent manner (Vassalli and Dijk, 2009) as a self-organizing property of any "viable neuronal assembly" (Krueger and Obál, 1993). Within this framework, evidence for discrete region specificity exists (Vyazovskiy et al., 2011). The most predominant delta rhythm generators in human cortex during sleep are the association areas of frontal cortex and parietal cortex (Ioannides et al., 2009), and each cortical region may have its own local delta rhythm generator (Mormann et al., 2008) interacting with the thalamic generator.

In local circuits during the wake state, an intimate, nested relationship exists between theta (and gamma) and delta (Lakatos et al., 2008) rhythms, with powerful implications for information processing (Schroeder and Lakatos, 2009). Delta and theta rhythms also appear to have a particularly intimate relationship during sleep: both rhythms are homeostatically coregulated during the sleep-wake cycle (Borbély et al., 1981) and increase together after periods of wakefulness (Franken et al., 1991). In addition, very low within-subject variability (Van Dongen et al., 2006) and covariability to sensory input are reported (De Gennaro et al., 2008). However, it is unlikely that these rhythms are facets of the same mechanism (Campbell and Feinberg, 2009). 
Here we demonstrate the mechanism underlying a purely neocortical delta rhythm generator and show a remarkable laminar, cell subtype and local subcircuit delineation between delta and nested theta rhythms. We show that spike timing during delta-nested theta rhythms controls an iterative, reciprocal interaction between deep and superficial cortical layers resembling the unsupervised learning processes proposed for laminar neural networks by Hinton and colleagues (Dayan et al., 1995; Hinton et al., 1995) and mimicking the alternating cortical dynamics of sensory and memory processing during wakefulness (Takeuchi et al., 2011).

\section{Materials and Methods}

Experimental methods. Coronal slices ( $450 \mu \mathrm{m}$ thick) containing secondary somatosensory/parietal area S2/Par2 were prepared from adult male Wistar rats $(\sim 150 \mathrm{~g})$ and maintained at $34^{\circ} \mathrm{C}$ at the interface between humidified $95 \% \mathrm{O}_{2} / 5 \% \mathrm{CO}_{2}$ and artificial CSF (ACSF) containing the following (in mM): $126 \mathrm{NaCl}, 3 \mathrm{KCl}, 1.25 \mathrm{NaH}_{2} \mathrm{PO}_{4}, 1 \mathrm{MgSO}_{4}, 1.2 \mathrm{CaCl}_{2}, 24 \mathrm{NaHCO}_{3}$, and 10 glucose. All surgical procedures were in accordance with regulations of the United Kingdom Animals (Scientific Procedures) Act, 1986. Persistent, spontaneous delta rhythms were induced by perfusion of the cholinergic agonist carbachol $(2 \mu \mathrm{M})$ and the $\mathrm{D}_{1}$ dopamine receptor antagonist SCH23390 $[R(+)$-7-chloro-8-hydroxy-3-methyl-1-phenyl-2,3,4,5-tetrahydro- $1 \mathrm{H}$-3-benzazepine hydrochloride] $(10 \mu \mathrm{M})$. Additional drugs were perfused in some experiments: pirenzipine $(10 \mu \mathrm{M}), \mathrm{AP}-5(50 \mu \mathrm{M})$, NBQX $(20 \mu \mathrm{M})$, SYM2206 [( \pm )-4-(4-aminophenyl)-1,2-dihydro-1-methyl-2propylcarbamoyl-6,7-methylenedioxyphthalazine] (10 $\mu \mathrm{M}), \mathrm{UBP} 302[(S)$ 1-(2-amino-2-carboxyethyl)-3-(2-carboxybenzyl)pyrimidine-2,4-dione] $(20 \mu \mathrm{M})$, gabazine (500 nM), CGP55845 [(2S)-3-[(15)-1-(3,4-dichlorophenyl)ethyl] amino-2-hydroxypropyl)(phenylmethyl)phosphinic acid] (1 $\mu \mathrm{M})$, carbenoxolone $(0.2 \mathrm{mM})$, octanol $(1 \mathrm{mM})$, quinine $(0.2 \mathrm{~mm})$, and $18 \beta$ glycyrrhetinic acid $(0.1 \mathrm{~mm})$ were all obtained from Tocris Cookson or Sigma.

Extracellular field potential recordings were taken with micropipettes (2-5 M $\Omega$ ) filled with ACSF. Intracellular recordings used pipettes with 2 M potassium acetate $(50-100 \mathrm{M} \Omega)$. Extracellular data were bandpass filtered at $0.1 \mathrm{~Hz}$ to $0.5 \mathrm{kHz}$, with intracellular direct current recordings low-passed filtered at $2.5 \mathrm{kHz}$. Stable oscillations were recorded $2 \mathrm{~h}$ after carbachol and SCH23390 application. Voltage-sensitive dye recordings from human frontal cortical tissue (removed as part of surgery to access a deep brain tumor not associated with epilepsy in the patient) were performed by incubating the tissue for $2 \mathrm{~h}$ in di-4-ANEPPS [4-(2-(6(dibutylamino)-2-naphthalenyl)ethenyl)-1-(3-sulfopropyl)pyridinium hydroxide inner salt] [Invitrogen; $5 \mu \mathrm{M}$ prepared from a stock solution in ethanol/DMSO (2:1), diluted 200:1 in oxygenated ACSF]. Epifluorescence from illumination at $532 \mathrm{~nm}$ (Verdi; Coherent) was monitored using a $4 \times$ objective, a dichroic mirror $(575 \mathrm{~nm})$, and a long-pass filter $(590 \mathrm{~nm})$ and imaged at $200 \mathrm{~Hz}$ with a $100 \times 100$ pixel CCD camera (MiCAM ULTIMA; RIKEN). Spatiotemporal spike and local field potential $(\mathrm{LFP})$ data were obtained using Utah probes $(10 \times 10$ electrodes, $0.4 \mathrm{~mm}$ separation) coupled to a Cyberkinetics amplifier (Blackrock Microsystems).

Power spectra were derived from Fourier analysis of $60 \mathrm{~s}$ epochs of data, and results were presented as mean \pm SEM. Spike and synaptic event detection was performed on the basis of peak transient deflections from mean membrane voltage. Cross-correlograms, phase, synchrony, and coherence measures were derived using scripts written in MATLAB (MathWorks). Interaction between cortical layers was performed using a Granger causality test. Sixty-second epochs of unfiltered data were downsampled to $0.5 \mathrm{kHz}$ and split into $2 \mathrm{~s}$ epochs. Each epoch was used to construct a bivariate autoregressive model (order of 20), and the best model for all epochs used estimate causality using the BSMART toolbox (Cui et al., 2008). Spike correlation data were analyzed using Neuroexplorer. Statistical significance was measured by paired/unpaired $t$ tests and one-way ANOVA tests. Results were deemed statistically significantly if $p<0.05$.

Simulation methods. We simulated a cortical column (without the thalamic portion), based on a program described by Traub et al. (2005).
The present model included 1000 superficial regular spiking (RS) pyramids, 50 superficial fast rhythmic bursting (or chattering) pyramids, 90 superficial basket cells (FS1), 90 superficial axoaxonic interneurons, 90 superficial low-threshold spiking (LTS) interneurons, 240 spiny stellate cells, 2000 deep tufted intrinsic bursting (IB) pyramids, 500 deep nontufted RS pyramids, 100 deep basket cells, 100 deep axoaxonic cells, and 100 deep LTS interneurons, all with intrinsic properties similar to the previous study. We did not include deep tufted RS cells in the present model. To simulate the $\mathrm{GABA}_{\mathrm{B}}$ dependence of the delta rhythm, we added an additional fast-spiking (FS) interneuron (FS2) modeled as a "neurogliaform"-type interneuron. Ninety superficial and 100 deep neurogliaform interneurons were small FS interneurons with increased soma/dendritic " $\mathrm{A}$ "-type $\mathrm{K}^{+}$conductance, rendering them "delayedspiking" neurons, in response to an injected current pulse. In our program, neurogliaform cells were the only ones to produce postsynaptic $\mathrm{GABA}_{\mathrm{B}}$ conductances; they produced $\mathrm{GABA}_{\mathrm{A}}$ conductances as well and were excited by AMPA/kainate receptors and by NMDA receptors (NMDARs).

Neurons were interconnected by chemical synapses and gap junctions. The connectivity of chemical synapses was similar to that in the study by Traub et al. (2005). In addition, superficial neurogliaform cells contacted all types of pyramidal cells (onto the apical dendrites of deep ones), as well as other superficial neurogliaform and basket cells. Deep neurogliaform cells contacted deep tufted pyramids, spiny stellates, and other deep neurogliaform cells, as well as deep basket cells. AMPA receptor (AMPAR)-mediated conductance time courses followed an alpha function. $\mathrm{GABA}_{\mathrm{A}}$ conductances rose abruptly and decayed following a singleexponential time course. NMDA conductances were described by the formalism of Traub et al. (1994), in which there is a product of a scaling factor, a purely time-dependent term, and a voltage- and $\left[\mathrm{Mg}^{2+}\right]$ dependent term (see also Traub et al., 2005). GABA ${ }_{B}$ conductances also followed a formalism from Traub et al. (1994) in which the conductance is zero for $10 \mathrm{~ms}$ and then is a scaling factor multiplied by a timedependent term ( $t$ in milliseconds):

$[1-\exp (-(t-10) / 38.1)]^{4} \times[10.2 \times \exp (-(t-10) / 122)$

$$
+1.1 \times \exp (-(t-10) / 587)] .
$$

Neurons were also coupled by gap junctions, which were placed only between homologous cell types (for example, deep tufted IB neurons only coupled electrically to other deep tufted IB neurons). Gap junctions were located on the dendrites of interneurons and on the axons of principal neurons. Spontaneous activity was driven by ectopic axonal spikes to superficial pyramidal cells (but not deep ones) and by tonic depolarizing currents to the basal dendrites of tufted IB pyramidal cells.

Differential equations were integrated with a second-order Taylor series method, with integration step of $2 \mu$ s. Programs were written in Fortran and compiled with the mpxlf command for the mpi parallel environment. Simulations were run on 24 nodes of an IBM 7040-681 AIX parallel machine. Simulation of $3 \mathrm{~s}$ of neural activity took $\sim 31 \mathrm{~h}$. Source code is available from R.D.T. (at rtraub@us.ibm.com).

\section{Results}

\section{Origin of the neocortical delta rhythm}

During NREM3 and NREM4, the neuromodulatory state of the mammalian brain is characterized by a low cholinergic and dopaminergic tones. To model this experimentally, we bathed rat neocortical slices in $2 \mu \mathrm{M}$ carbachol ( $1 / 10$ the amount required to generate cortical rhythms associated with cognitive function during waking) and $10 \mu \mathrm{M} \mathrm{SCH} 23390$ to block $\mathrm{D}_{1}$ constitutive dopaminergic activity at $\mathrm{D}_{1}$ receptors (Fig. 1 ). In the absence of any neuromodulatory manipulation, 10\% (3 of 28) of coronal slices containing parietal cortex generated spontaneous, persistent delta rhythms. With weak cholinergic activity alone, this rose to $48 \%$ (9 of 19) and with additional block of $\mathrm{D}_{1}$ receptors $80 \%$ (66 of 81 ; Fig. 1Bi). In this condition, persistent delta rhythms were observed with peak-trough field potential amplitude of $356 \pm 25$ 

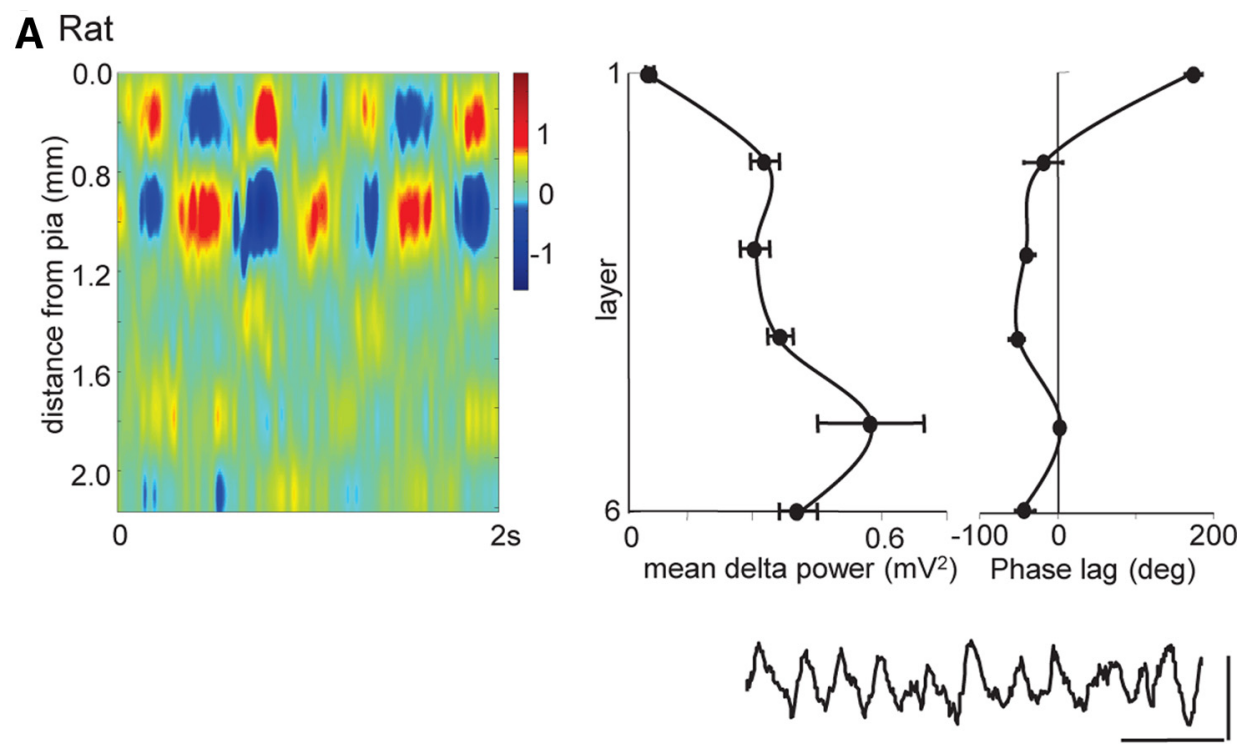

B i

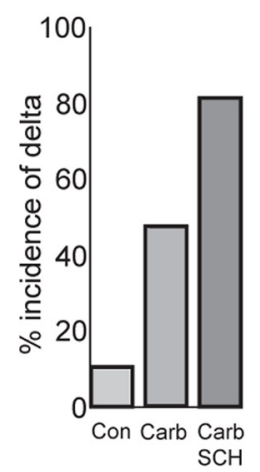

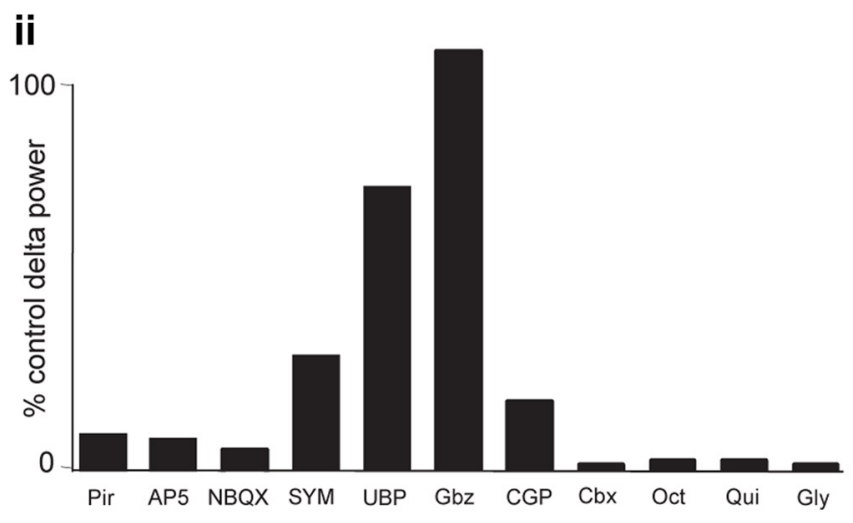

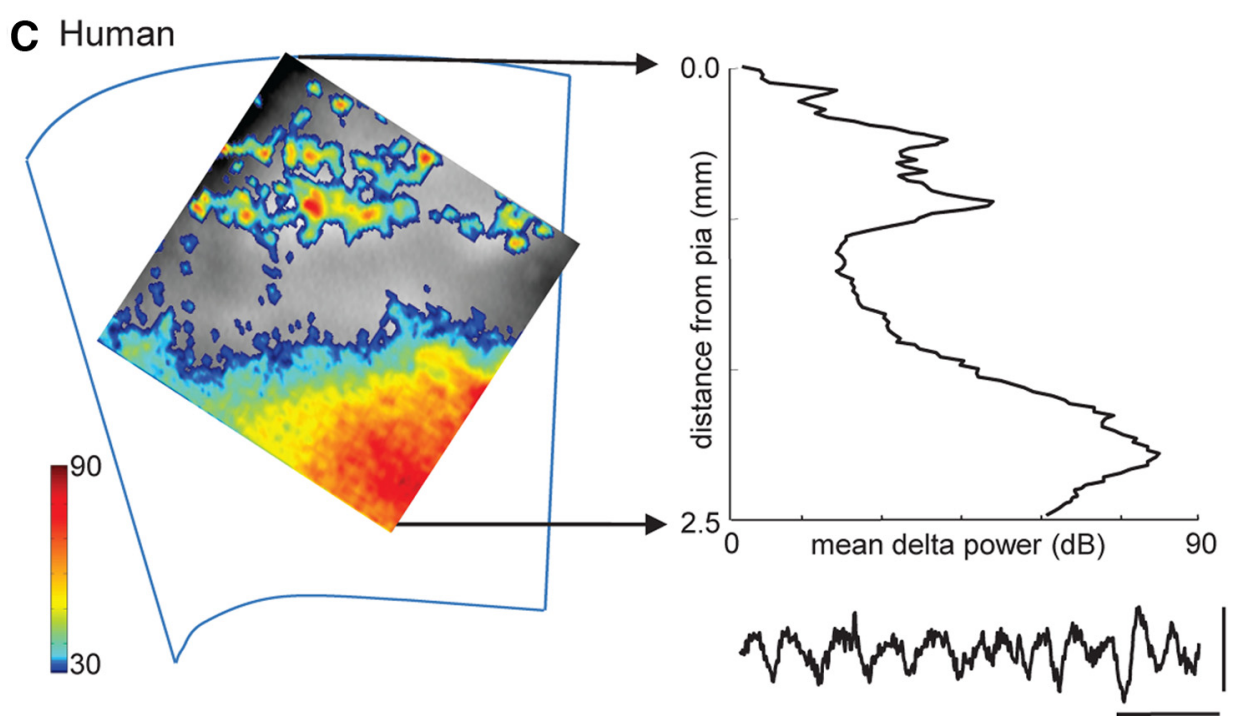

Figure 1. Basic properties of neocortical delta rhythms in vitro in human and rat tissue. $A$, Linear electrode array recording of persistent, spontaneous delta rhythms in rat parietal cortex. Image shows a $2 \mathrm{~s}$ epoch of delta activity as current source density plot. Note the superficial dominance of sink/source pairs. Graphsshow mean delta power $(n=5$, with $5 \times 20$ sepochs per $n)$ and laminar phase difference relative to layer 5 . Note the power maxima in layer 5 (as seen in human recordings in $C$ ) and the abrupt phase reversal between layers 1 and 2/3. Example trace taken from an electrode located in layer 5 . Calibration: 0.3 $\mathrm{mV}, 1$ s. B, Pharmacological profile of delta activity. $\boldsymbol{i}$, Incidence of spontaneous delta generation with neuromodulation. Con, Control; Carb, carbachol, $2 \mu \mathrm{m}$; SCH, SCH23390, $10 \mu \mathrm{m}$. ii, Changes in mean delta power $(n=5)$ after application of drugs affecting various network mechanisms: pirenzipine (Pir, $10 \mu \mathrm{m}) \mathrm{M}_{1} / \mathrm{M}_{3}$ blockade, AP-5 (50 $\left.\mu \mathrm{m}\right)$ NMDAR blockade, NBQX (20 $\left.\mu \mathrm{M}\right)$ AMPA/kainate receptor blockade,

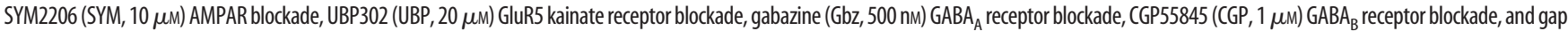
junction conductance decrease [carbenoxolone (Cbx, $0.2 \mathrm{~mm})$, octanol $(0 \mathrm{ct}, 1 \mathrm{mM})$, quinine (Qui, $0.2 \mathrm{mM})$, and $18 \beta$-glycyrrhetinic acid $(G l y, 0.1 \mathrm{~mm})$ ]. C, Voltage-sensitive dye imaging of persistent, spontaneous delta rhythms in human frontal cortex. Image shows delta power averaged over $5 \times 20$ s epochs. Color map adjusted to show delta power hard-thresholded at $30 \mathrm{~dB}$. Graph shows mean laminar distribution of delta power indicating maxima in layers $5 / 6$ and $2 / 3$. Example trace shows a $2 \times 2$ pixel binned time series of the raw fluorescence change. Calibration: $0.02 \% \delta F / F, 1 \mathrm{~s}$. 
$\mu \mathrm{V}$, power of $0.58 \pm 0.12 \mathrm{mV}^{2}$, and frequency of $2.1 \pm 0.3 \mathrm{~Hz}$. Delta rhythms were also generated in this experimental condition in other cortical association areas: temporal association area and frontal cortex. Only weak, slower events could be detected in primary sensory areas (S1 and Aul) (data not shown).

To further uncover the origin of the delta rhythm, we quantified the current source densities across laminae in parietal cortex. As with data from human invasive electrode studies (Csercsa et al., 2010), dominant source/sink pairs were seen in superficial layers in Utah recordings (Fig. 1A). This was associated with an abrupt phase reversal when comparing pairwise glass electrode recordings, with reference electrode in layer 5, between layers 2 and $1\left(-18 \pm 20^{\circ}\right.$ vs $175 \pm 8^{\circ}, n=5$; Fig. $\left.1 A\right)$. However, both phase reversal and source/sink pair location were displaced from the layers in which peak delta power was seen. In all association areas, delta power was clearly largest in layer 5 (see Discussion). To determine whether this dominance of the delta rhythm power in deep layers was translatable to human neocortex in this experimental model, we used voltage-sensitive dye recordings from non-epileptic human frontal cortical tissue. In the neuromodulatory environment used for rat studies, human association cortex also generated persistent delta rhythms (Fig. 1C). Mean frequency was not different from rat $(2.4 \pm 0.5 \mathrm{~Hz}, n=6$ epochs over $3 \mathrm{~h}$ ). As with the rodent model, peak power was clearly localized to deep layers, with additional, smaller peaks in power around layers 2 and 3.

Pharmacological clues to the mechanism underlying the delta rhythm suggested a complex interaction of multiple factors (Fig. 1Bii). The dependence on cholinergic drive appeared to be predominantly via muscarinic receptors: pirenzipine $(10 \mu \mathrm{M})$ reduced delta power to below $10 \%$ of control values. In terms of synaptic excitation, blockade of either NMDARs alone (with 50 $\mu \mathrm{M}$ D-AP-5) or both AMPARs and kainate receptors $(20 \mu \mathrm{M}$ NBQX) also reduced delta power to $<10 \%$ of control values. However, blockade of AMPARs or kainate receptors alone did not have such a dramatic effect on delta power, suggesting that a general reduction in excitation was required. There was a clear divergence in the effects of synaptic inhibition on the delta rhythm. Reduced $\mathrm{GABA}_{\mathrm{A}}$ receptor-mediated excitation increased mean delta power, whereas reduced $\mathrm{GABA}_{\mathrm{B}}$ receptormediated inhibition reduced delta power to $17 \pm 5 \%$ of control $(n=5$; Fig. 1 Bii). In addition, a range of drugs reducing gap junction conductance (each with different nonspecific effects) all nearly abolished the delta rhythm. Together, these pharmacological manipulations pointed to multiple mechanisms combining to generate the rhythm seen. To attempt to identify the key mechanisms, we next examined the outputs and synaptic inputs of different association neocortical neurons.

\section{Neuronal subtypes in layer 5 involved in the delta rhythm}

Both a subset of FS interneurons and all intrinsically bursting principal cells were seen to generate bursts of spike outputs on almost every delta period phase locked to concurrently recorded layer 5 field potentials (Fig. 2). In each case, bursts of spikes were seen to ride on slow compound EPSPs. Mean spike incidence per delta period for delta-locked FS cells was $6 \pm 2$ (100 periods each in $n=4$ neurons; Fig. 2B, FS1). Excitatory inputs were characterized by near-continuous occurrence of small, fast EPSPs $(1.6 \pm 0.8 \mathrm{mV}, \tau d=2.7 \pm 0.3 \mathrm{~ms})$. Superimposed on this lowlevel "noise" were large compound EPSPs that appeared to be made up of intense barrages of the small single EPSPs see during the quiescent part of each period. Mean peak amplitude of these delta phase-locked compound events was $13 \pm 3 \mathrm{mV}$ from -70
$\mathrm{mV}$ membrane potential. Interestingly, pooled power spectral analysis of FS EPSP traces (60s long, $n=4$; Fig. $2 B$ ) revealed a second, smaller more spectrally spread peak in addition to the dominant delta frequency. Peak frequency of this additional rhythmic component was within the theta range $(4.8 \pm 1.0 \mathrm{~Hz})$.

Bursts of spiking from layer 5 IB neurons were also seen on each delta period (Fig. 2C). Mean spike incidence per delta period was greater than that seen in FS cells $(10 \pm 3,100$ periods each in $n=6$ neurons), and spikes arose from large compound somatic EPSPs $(9.4 \pm 2.0 \mathrm{mV}$ amplitude from $-70 \mathrm{mV})$. Although the overall active period of IB neurons coincided with a plateau depolarization, EPSP shapes were characteristically ramped, increasing in amplitude as the active period progressed, suggesting that initial spiking was related to the intrinsic burst ability of these neurons and the later spikes directly arising from the network EPSP. Synaptic inhibition in IB neurons consisted of two components. During the active phase of each delta period, IB cells received a barrage of fast IPSPs that weakly temporally summed until spike termination. In contrast, the quiescent part of each delta cycle was associated with a slow hyperpolarizing potential resembling $\mathrm{GABA}_{\mathrm{B}}$-mediated IPSPs in these cells. Mean power spectra of these synaptic events recorded at a mean membrane potential of $-30 \mathrm{mV}$ also showed two components: a dominant, sharp peak at theta frequency $(4.2 \pm 0.4 \mathrm{~Hz}$, see above for comparison with FS EPSPs) and a weaker, more spectrally spread peak at delta frequency.

\section{Neuronal subtypes involved in layer 5 in the nested theta rhythm}

Not all FS cells showed the tight temporal relationship between spiking and the field delta rhythm described above. A subset of neurons with near-identical spike shapes and response to depolarizing current steps to those described above were found to generate outputs dominated by single action potentials at theta frequency $(4.5 \pm 0.5 \mathrm{~Hz}, n=3$ neurons from 3 slices; Fig. $3 B$, FS2). Occasional intense bursts of action potentials were also generated in this neuron subtype phase locked to the field delta rhythm (mean burst incidence, 0.4 per delta period). The contrasting outputs of FS1 and FS2 interneurons appeared to be a consequence of their respective synaptic excitation profiles. Slow excitatory events phase locked to the field delta rhythm were much weaker and more erratic in FS2 cells. Mean amplitude was $5.2 \pm 1.4 \mathrm{mV}(p<0.05$ compared with FS1 delta-frequency EPSPs). The theta-frequency spike incidence matched a different set of synaptic inputs: fast EPSPs $(4.4 \pm 0.8 \mathrm{mV}, \tau d=2.5 \pm 0.4$ $\mathrm{ms}$ ) occurred in a highly rhythmic manner in each FS2 cell recorded. The combination of these two types of input resulted in a broad mean spectrum with modal peaks at delta frequency $(2.0 \pm$ $0.4 \mathrm{~Hz})$ and theta frequency $(4.6 \pm 0.8 \mathrm{~Hz})$.

Layer 5 principal cells showed a remarkable divergence in spike behavior and inputs. Unlike the intense bursting of IB cells with the field delta rhythm, layer 5 RS neurons did not burst. Instead, a range of spiking patterns from single spikes on each delta period to near-continuous theta-frequency spiking was seen (Fig. 3C). Mean spike incidence histograms revealed a modal peak at $4.4 \pm 1.0 \mathrm{~Hz}(n=9)$. This pattern of outputs did not correspond to EPSP inputs seen in RS neurons. As with IB neurons, compound excitatory inputs occurred phase locked to the field delta rhythm. However, they were significantly smaller ( $4.1 \pm 0.6 \mathrm{mV}, p<0.05$ compared with IB neuron EPSPs) and showed a different ramped profile. Although IB EPSPs ramped up in amplitude during the active phase of each delta period, RS EPSPs ramped down. IPSP inputs also differed between the two 
A

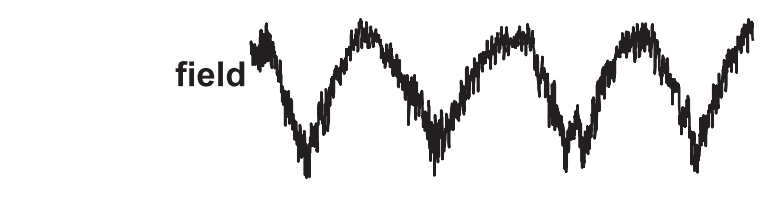

B

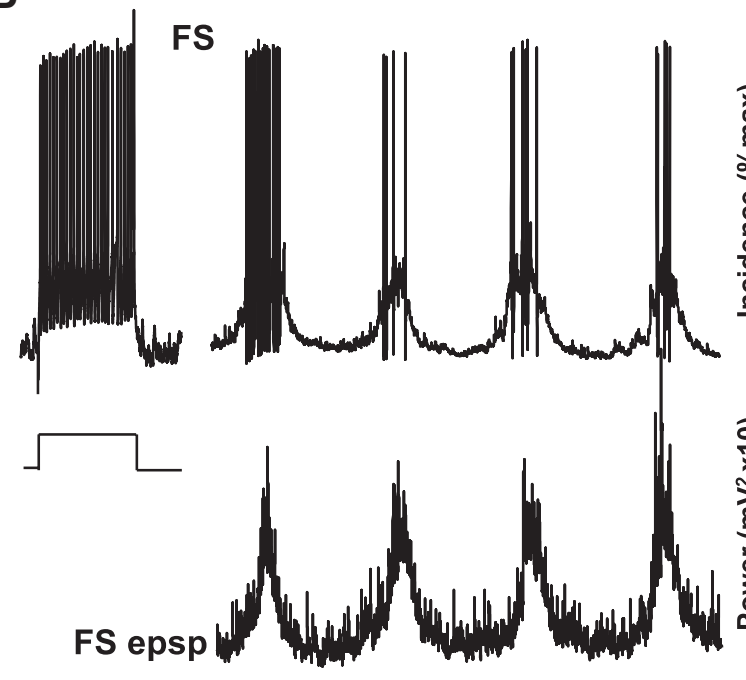

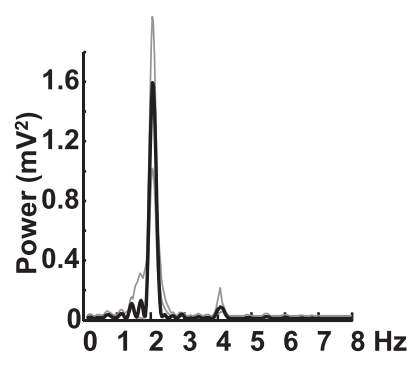
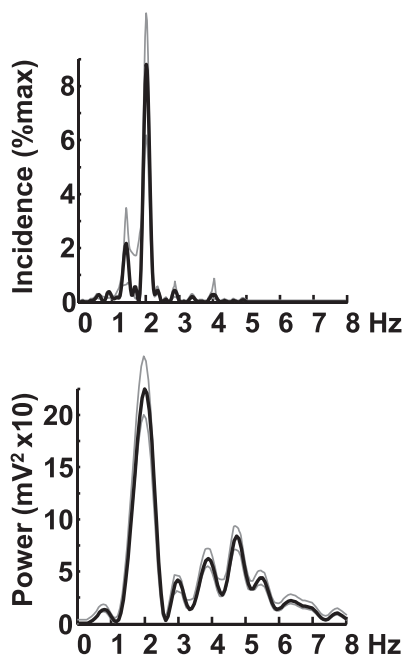

C
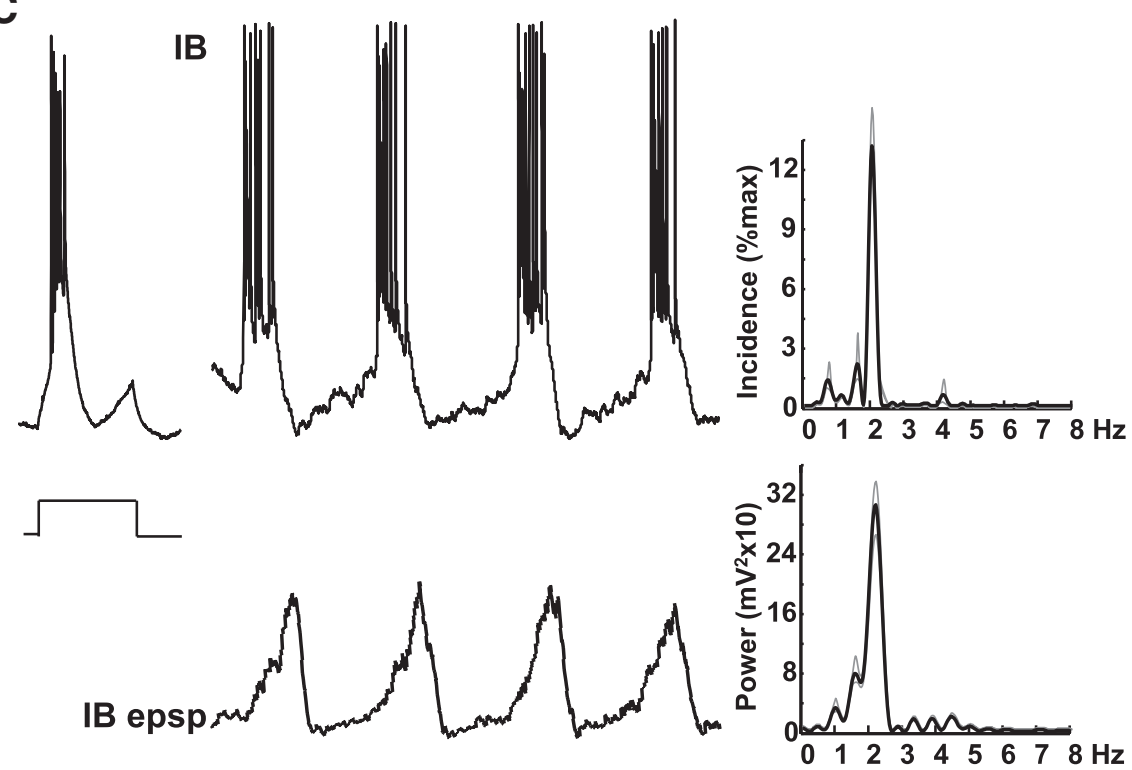

IB epsp

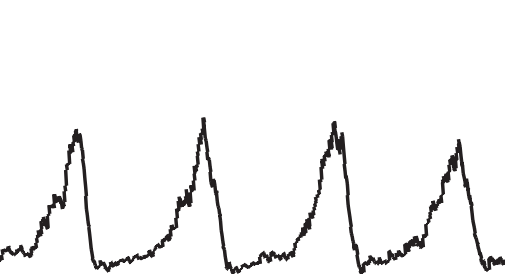

$\begin{array}{lllllllllll}0 & 1 & 2 & 3 & 4 & 5 & 6 & 7 & 8 & \mathrm{~Hz}\end{array}$
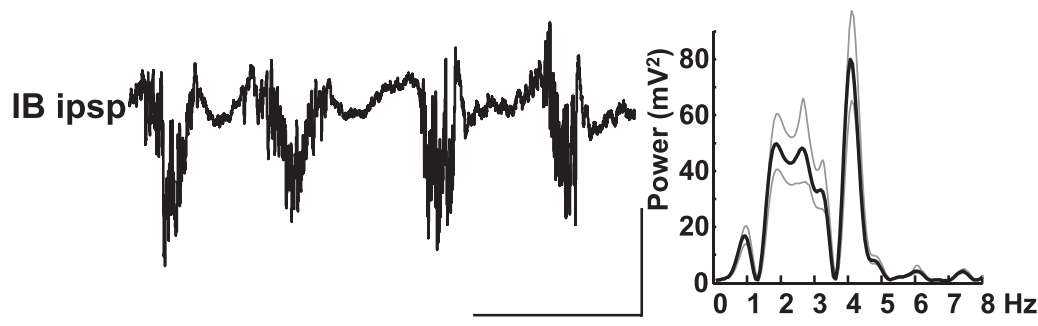

Figure 2. Delta rhythms are generated by layer $5 \mathrm{IB}$ neurons. $A$, Example trace showing a layer $5 \mathrm{LFP}$ recording of delta activity. Spectrum shows a tight, single modal peak at $\sim 2 \mathrm{~Hz}$. Data plotted as mean (black line) and SEM (gray lines). $\boldsymbol{B}$, Example recordings from a non-accommodating, FS interneuron in layer 5 . Response to step injection of $+0.2 \mathrm{nA}$ current for 200 ms demonstrates the intrinsic spiking behavior. Top trace shows spontaneous bursts of spike generation at resting membrane potential phase locked to

cell types. No trains of fast IPSPs were seen in RS neurons during the active phase of the delta period, and the quiescent phase was often interrupted by additional IPSP inputs. IPSPs seen had kinetics intermediate to the fast and slow events recorded in IB neurons $(6.7 \pm 1.1$ $\mathrm{mV}, \tau d=21.2 \pm 1.3 \mathrm{~ms}$ ).

This complex pattern of different outputs from layer $5 \mathrm{FS}$ neurons and principal cells was captured by the revised cortical column computational model used in this study (see Materials and Methods). The dominant, delta-locked spike outputs occurred in model IB and FS2 neurons. IB neuron spiking was initiated by predominantly NMDAR-mediated IB-IB recurrent excitatory connections and terminated by a combination of the strong intrinsic afterhyperpolarization in this neuron subtype and a phasic $\mathrm{GABA}_{\mathrm{B}}$ receptor-mediated slow IPSP (Fig. 4). This latter network component came from FS2 interneurons modeled as neurogliaform-like cells that generated intense bursts on each delta period (a burst incidence seen in experimental FS2 cells) interspersed with near-continuous thetafrequency single spikes (compare Figs. 3B, 4). In contrast, basket-like FS1 interneurons generated weaker spike trains at delta frequency, and layer 5 RS-like cells generated delta-nested single spikes or spike pairs, or continuous theta-frequency spike outputs. This model confirmed the pharmacological data (Fig. 1Bii) implicating NMDARmediated excitation between IB neurons

$\leftarrow$

the concurrently recorded field $(\boldsymbol{A})$. Top histogram shows mean burst incidence at delta frequency. Bottom trace shows membrane potential at $-70 \mathrm{mV}$ (mean) revealing large, slow, regular depolarizations interspersed with more rapid but smaller, faster EPSPs. Bottom spectrogram shows that mean power of EPSPs onto FS cells had a modal peak at delta frequency but with a smaller additional peak in the theta $(\sim 5$ $\mathrm{Hz}$ ) band. C, Example recordings from an IB neuron in layer 5. Step depolarization with $0.2 \mathrm{nA}(200 \mathrm{~ms})$ reveals the intrinsic bursting behavior of this cell type. Top trace shows spontaneous bursts of spike generation at resting membrane potential phase locked to the layer 5 field delta rhythm (note that these traces were not concurrently recorded with the example field in $\boldsymbol{A}$ ). Top histogram demonstrates mean burst incidence at delta frequency. Middle trace shows a recording from the same neuron held at $-70 \mathrm{mV}$ (mean) revealing large, ramped EPSPs underlying the bursting behavior. Mean power spectra again show peak incidence of EPSPs at delta frequency. Bottom trace shows activity in the same cell held at $-30 \mathrm{mV}$ to reveal IPSP inputs. IPSPs were complex, consisting of deltafrequency bursts of higher frequency, fast IPSPs interleaved with single, slow hyperpolarizations. Mean spectra (bottom graph) of such behavior in $n=5$ neurons exposed a bimodal power distribution with peaks at delta and theta frequencies. Calibration: $200 \mathrm{mV}$ (field), $20 \mathrm{mV}$ (resting membrane potential), $10 \mathrm{mV}$ ( -70 and $-30 \mathrm{mV}$ recordings), $0.5 \mathrm{~s}$. 


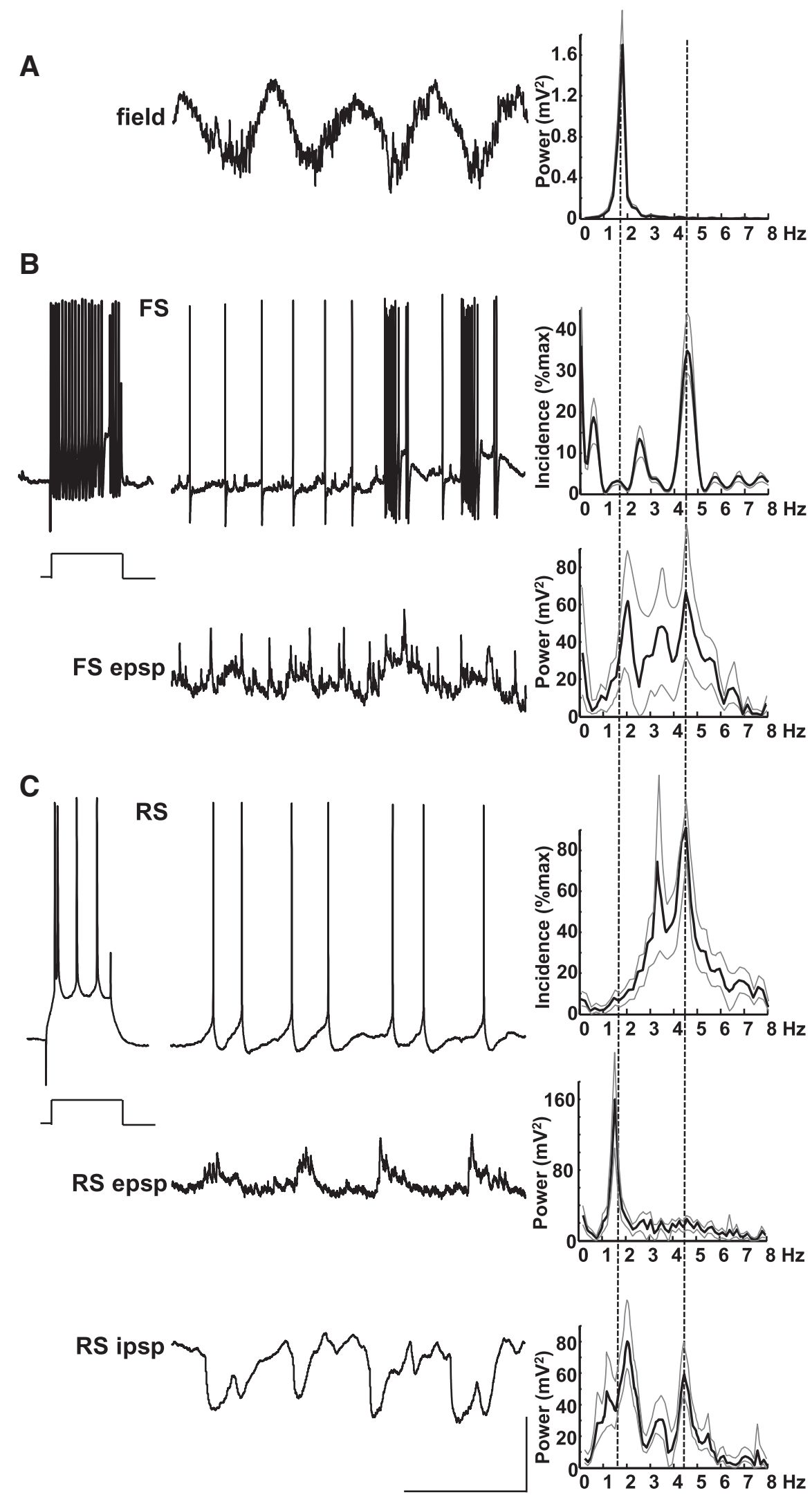

Figure 3. Layer $5 \mathrm{RS}$ neurons produce theta-frequency spike outputs. $\boldsymbol{A}$, Example trace showing a layer $5 \mathrm{LFP}$ recording of delta activity. Spectrum shows a tight, single modal peak at $\sim 2 \mathrm{~Hz}$ as in Figure 2. $\boldsymbol{B}$, Example recordings from a non-accommodating, FS interneuron in layer 5. Response to step injection of $+0.2 \mathrm{nA}$ current for $200 \mathrm{~ms}$ demonstrates the intrinsic spiking behavior. Top trace shows sporadic bursts of spike generation at resting membrane potential phase locked to the concurrently recorded field $(\boldsymbol{A})$. Note also predominant theta-frequency spike generation. Top histogram shows mean spike incidence at theta frequency. Bottom trace shows membrane potential at $-70 \mathrm{mV}$ (mean) revealing small, slow, regular depolarizations interspersed with more rapid and $\mathrm{GABA}_{\mathrm{B}}$ receptor-mediated inhibition as the primary features of the layer 5 delta rhythm generator. It also suggested the layer 5 theta generator was mediated by a combination of RS neuron intrinsic properties and synaptic inputs.

Layer 5 theta outputs are highly labile and manifest in the layer $2 / 3$ LFP

The model data predicted that transient, theta-frequency epochs of spikes from RS neurons would be highly sensitive to tonic excitatory drive to this cell type, with these cells being only weakly influenced by the layer 5 delta rhythm. A change in tonic drive of $0.2 \mathrm{nA}$ to model RS neurons was sufficient to change outputs from single, delta-locked spikes to this continuous theta-frequency output (Fig. 5A). During delta rhythms in association cortical slices, RS cell spike outputs could be modified across this range by injection of a small amount of tonic current $(\sim 0.1 \mathrm{nA})$. A mean membrane potential difference of $5.2 \pm 0.5 \mathrm{mV}$ was sufficient in each case to transform single, delta-locked spikes to continuous theta-frequency spiking. Over an even narrower range of membrane potentials, a stable theta burst of output (two to three spikes) could be generated. Interspike intervals within these brief bursts and during continuous spike were the same (170 \pm 15 vs $185 \pm 20 \mathrm{~ms}$, respectively, $p>0.1)$. To quantify the extent of the influence of the delta-frequency EPSPs in these neurons (Fig. $3 C$ ), spike probability relative to peak positivity of the layer 5 delta LFP was calculated. Despite the difference in spike output patterns, there was a peak in spike incidence 150-180 ms into these wave-triggered av-

but smaller, faster EPSPs with large events occurring at theta frequency. Bottom spectrogram shows mean power of EPSPs onto FS cells had a bimodal peak at delta and theta frequency. Lines plotted show means of each of the three cells recorded.C, Example recordings from an RS neuron in layer 5. Step depolarization with $0.2 \mathrm{nA}(200 \mathrm{~ms}$ ) reveals the $\mathrm{RS}$ behavior of this cell type. Top trace shows spontaneous spike generation at resting membrane potential is dominated by single or double spikes per delta period (note that these traces were not concurrently recorded with the example field in $A$ ). Top histogram demonstrates mean spike incidence approximately at theta frequency. Middle trace shows a recording from the same neuron held at $-70 \mathrm{mV}$ (mean) revealing small compound EPSPs occurring at delta frequency (from mean power spectrum on the left). Bottom trace shows activity in the same cell held at $-30 \mathrm{mV}$ to reveal IPSP inputs. IPSPs were complex, consisting of both delta- and theta-frequency components. Note the absence of the runs of fast IPSPS seen in the FS cell in Figure 2. Calibration: $200 \mu \mathrm{V}$ (field), $20 \mathrm{mV}$ (resting membrane potential), $10 \mathrm{mV}$ ( -70 and $-30 \mathrm{mV}$ recordings), $0.5 \mathrm{~s}$. 

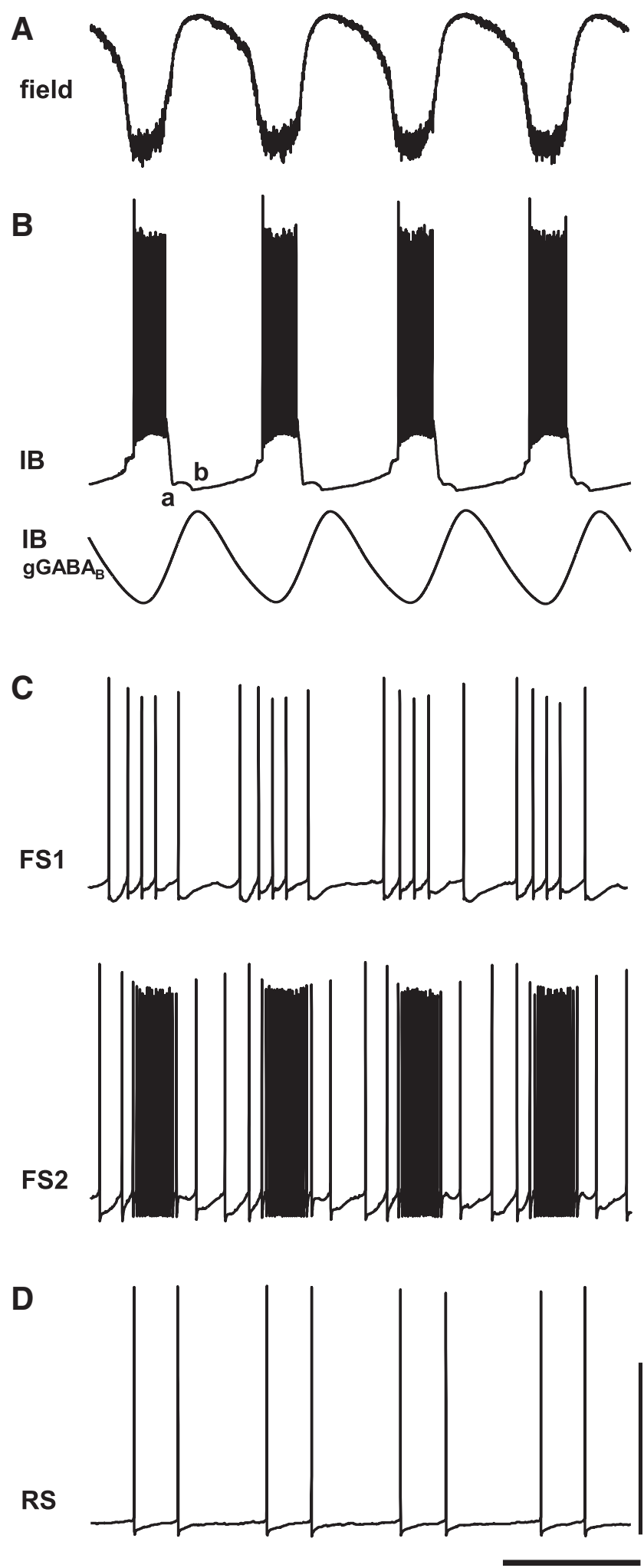

Figure 4. Computational model predicts local networks of $I B$ neurons and $G A B A_{B}$ receptormediated inhibition are necessary and sufficient to generate delta rhythms. $A$, Model layer 5 LFP (inverted sum of all synaptic inputs to IB neurons). $\boldsymbol{B}$, Example simulation of the behavior of an IB neuron demonstrating delta activity as periodic bursts of action potentials (top trace). The quiescent period between bursts is composed of an initial AHP from the IB neurons ( $a$ compared with Fig. $2 C$ and a later $G A B A_{B}$-mediated IPSP $(\boldsymbol{b})$. Bottom trace shows an example simulation of the periodic $G A B A_{B}$ receptor-mediated conductance in layer $5 \mathrm{IB}$ neurons. $C$, $F S$ neurons in layer 5 were modeled as two types receiving different profiles of excitatory inputs from layer 5 pyramidal cells (see Materials and Methods). Those receiving greater tonic excitation erages (at the beginning of the active phase of each delta period; Fig. 5A)

Despite the clear presence of this theta-generating subcircuit within layer 5, the LFP was dominated by the IB neuronmediated delta rhythm. However, a field manifestation of this delta-nested theta activity was seen in superficial layers (Fig. 5B). Concurrent LFP recordings from layer 5 and layer 2 showed a phase reversal of the delta component of the rhythm (Fig. 1A). However, additional detail in the superficial layer LFP suggested higher-frequency components. Spectrograms of activity in the two layers revealed a clear, iterative presence of power within the theta band only in superficial recordings. Therefore, we examined cellular activity patterns in layers $2 / 3$ in more detail.

\section{Cellular responses in superficial layers}

RS neurons in layer $2 / 3$ spiked sparsely during the delta rhythm. Mean spike incidence per delta period was $0.6 \pm 0.2(n=14$ neurons from 11 slices). Spike timing relative to the LFP delta rhythm was highly variable with two clear maxima spread across the active phase (data not shown). Examination of EPSP profiles revealed a possible source for this: most delta periods were associated with compound EPSPs in superficial RS neurons with clear dual components (Fig. 6B). Peak EPSP amplitude was $5.5 \pm 0.6$ $\mathrm{mV}$ (from $-70 \mathrm{mV}$ mean membrane potential), and the profile of these events looked remarkably similar to the spike incidence profile in layer $5 \mathrm{RS}$ neurons in the narrow range of dual spike generation (Fig. 5A, black line). Spectral analysis of these superficial layer RS EPSPs also revealed dual peaks at delta and theta frequency. In contrast, IPSPs received by superficial RS neurons had only a relatively weak delta component to their spectra and almost no power in the theta band. The source of these compound IPSPs within the superficial layer consisted of at least local FS and LTS interneurons (Fig. 6C,D). Both interneuron subtypes generated spike bursts phase locked to the field delta rhythm, with outputs from FS cells more intense than LTS cells (7.2 \pm 2.0 vs $2.2 \pm 1.0$ spikes per delta period, respectively, $n=3$ and 4 ). LTS cell EPSP recordings showed almost no evidence for thetafrequency inputs, but superficial FS cell excitatory inputs were more complex. As with layer 2/3 RS cells, FS cells in these layers exhibited dual-compound EPSPs approximately on every other delta period (Fig. 6D).

\section{Spike/field coherence reveals a reciprocal laminar interaction} afforded by delta-nested theta rhythms

The above demonstration of overt theta-frequency inputs onto superficial RS neurons despite a near absence of local theta generation in other superficial neurons suggested a degree of interplay between the theta source in layer 5 and the pattern of activity seen in superficial layers. To address this, we used Utah electrode arrays to concurrently record unit activity from all layers simultaneously. As with intracellular data, layer 5 units could be divided into two clearly different output patterns. Of the 52 layer 5 units recorded (from seven slices), 23 demonstrated intense bursts on each delta period ( $7.8 \pm 0.5$ spikes per period) in a manner similar to that seen for intracellular recordings from IB

(FS2, modeled as neurogliaform-like cells) demonstrated more intense spike bursts interspersed with theta-frequency single spikes (compare with Fig. 3B). D, Example trace of activity in non-tufted, layer $5 \mathrm{RS}$ cells from the same simulation as $\boldsymbol{A}-\boldsymbol{C}$. Note the absence of deltafrequency bursts, being replaced by doublet spikes with interspike interval reflecting theta period, occurring every field potential delta period. Calibration arbitrary (field and IB $\left.G A B A_{B}\right): 50$ $\mathrm{mV}$ (spike behavior examples), $0.5 \mathrm{~s}$. 

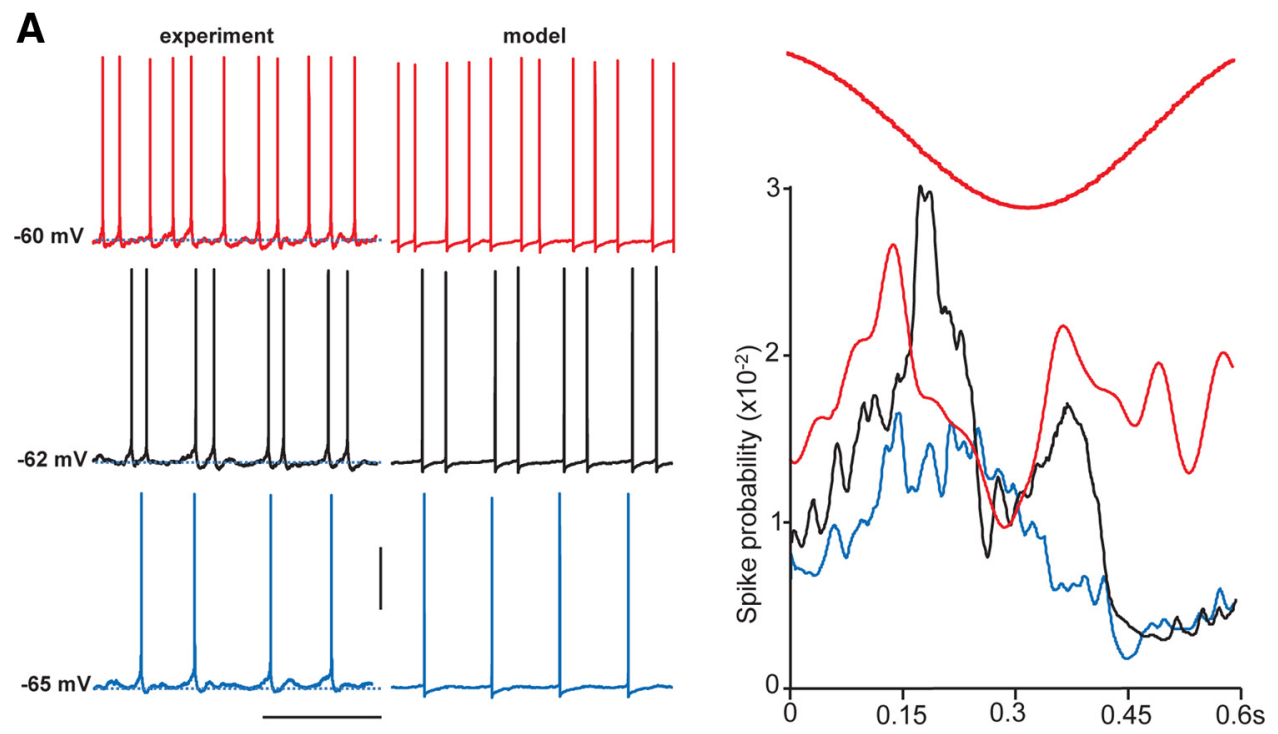

B

L2 field
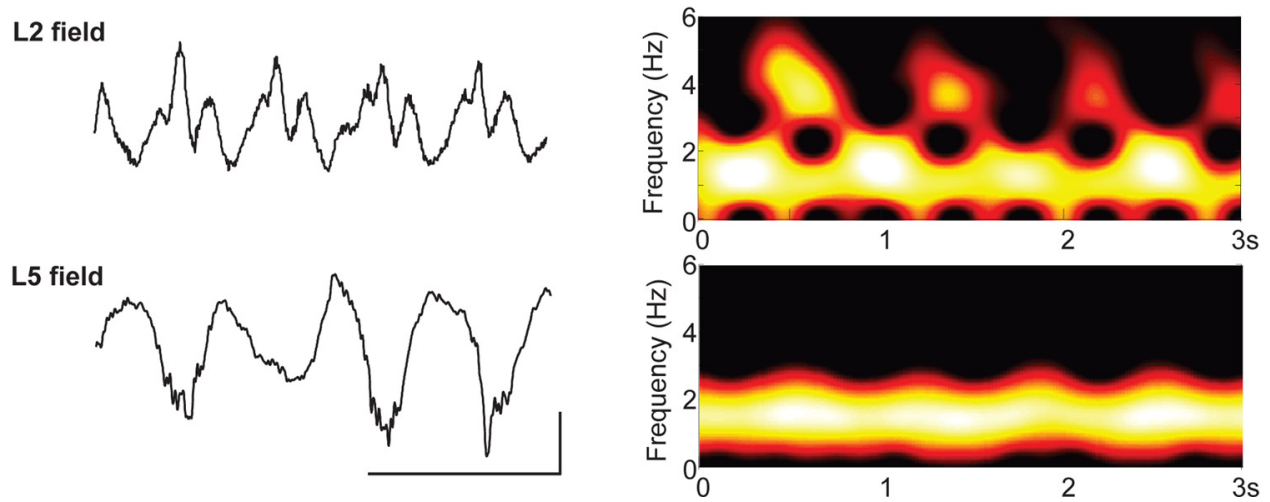

Figure 5. Layer 5 RS neuron theta spiking is only nested within delta rhythms over a narrow range of membrane potentials: outputs coincide with superficial layer field potential theta transients. $A$, Example traces (left) from a layer $5 \mathrm{RS}$ neuron held at mean membrane potentials varied from -65 to $-60 \mathrm{mV}$. Note at more hyperpolarized levels that the neuron fires only once on each delta period, whereas at more depolarized membrane potentials, firing is continuous at theta frequency. Example traces (right) show spiking behavior in three model layer $5 \mathrm{RS}$ cells in which the population received a range of tonic drives. Note the neuron with highest drive spikes continuously at theta frequency, whereas the neuron with lowest drive fires only single spikes at delta frequency. Graph shows mean spike probability, from experiments, during a field delta period (10 ms bins) from seven layer $5 \mathrm{RS}$ neurons held at $-65 \mathrm{mV}$ (blue), $-62 \mathrm{mV}$ (black), and $-60 \mathrm{mV}$ (red). Calibration: $20 \mathrm{mV}, 0.75 \mathrm{~s}$. B, Brief bursts of theta-frequency activity are manifest in superficial layer LFPs but not those from layer 5 . Example traces show concurrently recorded fields from layers 2 and 5 along with corresponding spectrograms showing the theta bursts nested within the dominant delta rhythm. Calibration: $50 \mu \mathrm{V}, 0.5 \mathrm{~s}$.

neurons (compare Figs. $2 C, 7 A$ ). The remaining active units detected in layer 5 had a lower spike incidence $(2.8 \pm 0.8$ spikes per delta period) and were weakly related to concurrently recorded delta LFP timing, as seen for layer 5 RS neurons (compare Figs. $3 C, 5 A)$. In superficial layers, a total of 32 sparsely spiking units were recorded ( $n=7$ slices), with a mean incidence of $0.6 \pm 0.2$ spikes per delta period, resembling the patterns seen with intracellular recordings from layer 2/3 RS neurons (Fig. 6B).

The presumed layer 5 and layer 2/3 RS units were used, in combination with the concurrently recorded layer 5 delta LFP, to investigate interlaminar interactions in detail. Direct crosscorrelations between presumed layer 5 and layer 2/3 RS units revealed little in the way of temporal interaction between the two cell types (Fig. 7B). However, when both sets of spike times were correlated with the common delta LFP, a distinct pattern emerged. When aligned with the peak negativity of the delta rhythm, mean spike correlations showed dual peaks in both deep and superficial RS units. Interestingly the interpeak interval was different for deep versus superficial RS cells ( $162 \pm 12$ vs $210 \pm 22$ $\mathrm{ms}$, respectively). In addition, peaks were locked to the delta rhythm in such a way that a reciprocal interaction between layers appeared to be taking place. From the beginning of the delta active period, superficial RS unit spiking peaked at $\sim 25 \mathrm{~ms}$ before deep RS unit spiking peaked. The temporal order of the second set of peaks was reversed so that deep RS unit spiking peaked before those in superficial layers.

The reciprocal nature of spike times between deep and superficial RS units was mirrored in directed coherence estimates from concurrently recorded deep and superficial layer LFPs (Fig. 7C). Again, activity underlying superficial layer field potentials appeared to be causal to corresponding deep layer activity at theta frequencies in the first part of the delta active period. The system appeared to reverse with deep layer activity causal to superficial LFPs for the later active phase of each delta period. Delta activity itself was always directed from deep to superficial layers throughout each period.

\section{Discussion}

The data presented here demonstrate the ability of association cortical local circuits to generate delta rhythms. The core mech- 
A

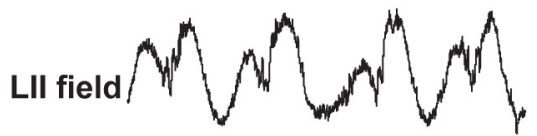

B
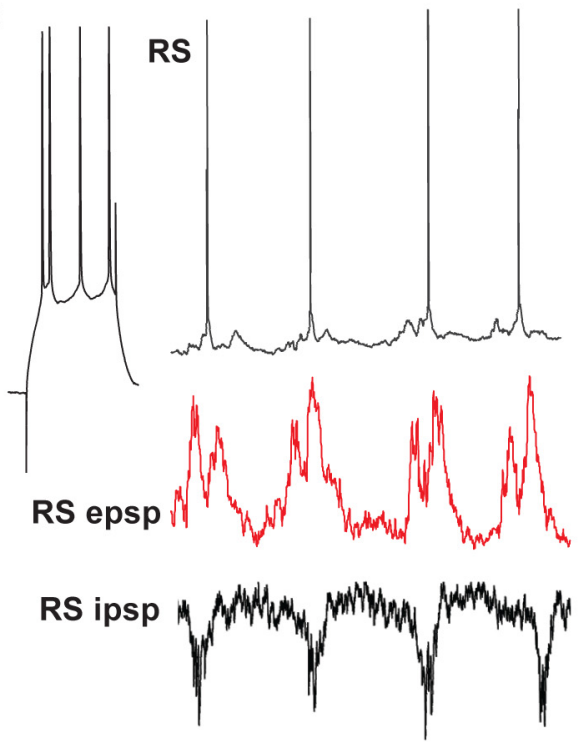

C
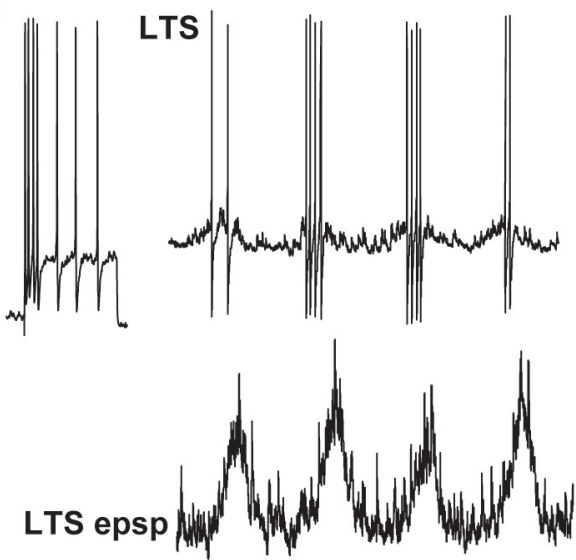

D
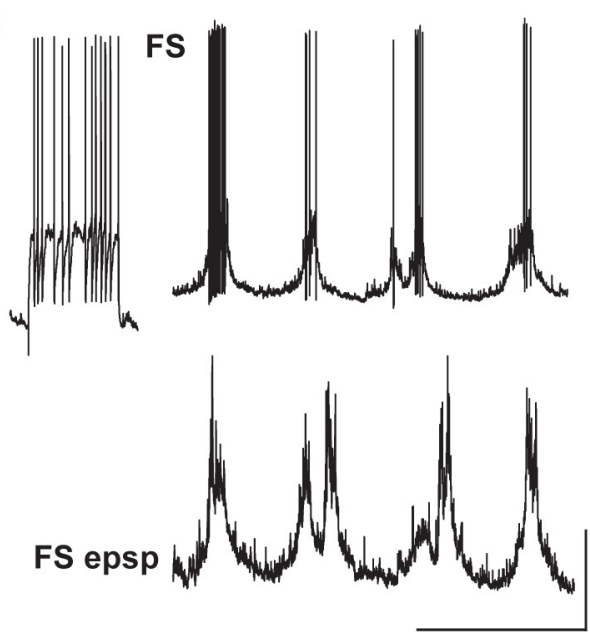
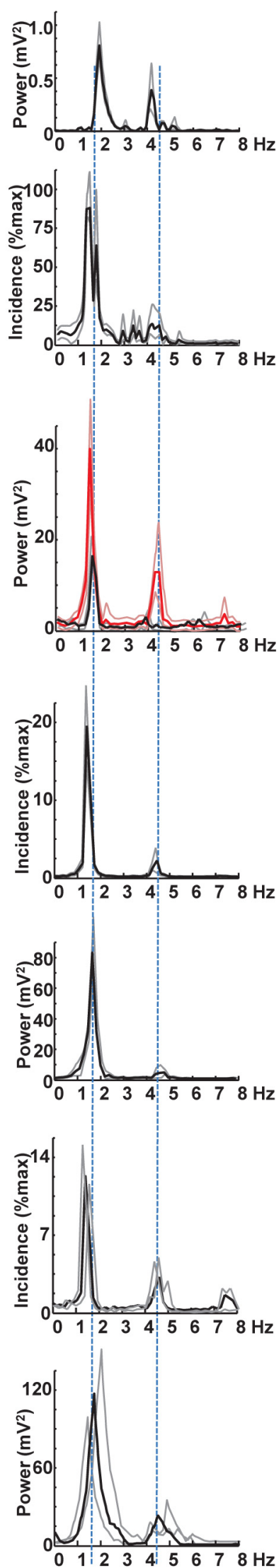

Figure 6. Superficial layer field theta bursts are most evident in excitatory synaptic inputs to layer $2 / 3 \mathrm{RS}$ neurons. $\boldsymbol{A}$, Example LFP from layer 2 with corresponding power spectrum showing both theta and delta peaks. $\boldsymbol{B}$, Example of superficial layer RS neuron behavior. RS neurons were defined by their spike response to $0.2 \mathrm{nA}, 200 \mathrm{~ms}$ depolarizing step. These neurons fired sparsely $(<1$ spike per delta period on average) but received robust compound EPSPs with clear double peaks (middle, red, trace). In contrast,

anism involved the activation of networks of IB neurons with cell bodies located in layer 5 , as seen for up/down states in mice in vivo (Beltramo et al., 2013). These neurons have been shown to be densely interconnected with both excitatory synapses and gap junctions (Mercer et al., 2006; Lefort et al., 2009). However, as seen with human recordings (Csercsa et al., 2010), current source density measures indicated that the major source of synaptic input was far more superficial, suggesting dominance of excitation onto the distal dendrites of these layer 5 neurons in which NMDAR-containing synapses are prevalent. Reduced gap junction conductance or blockade of NMDARs reduces slowwave sleep, the neocortical delta rhythm, and layer 5 neuron bursting (Fig. 1; Armstrong-James and Fox, 1988; FrancoPérez and Paz, 2009). In addition, generation of intense bursts from interneurons appeared to underlie the slow, $\mathrm{GABA}_{\mathrm{B}}$ receptor-mediated IPSP separating the active phase of each delta period, perhaps through volume conduction of GABA overspill from intensely active synapses and/or neurogliaform neuronal output (Oláh et al., 2009). Indeed, the core delta rhythm could be simulated with remarkable, neuron subtype-specific fidelity in a computational model driven by recurrent IB neuronal connectivity and feedback activation of interneurons, including neurogliaform cells (Fig. 4).

In contrast, the nested theta rhythm was generated by activity in layer 5 RS neurons. These were seen to be weakly activated in a delta phase-locked manner consistent with the existence of IB-to-RS excitatory synaptic connections (Lefort et al., 2009), with periods set by intrinsic properties and IPSPs. Outputs from both layer 5 cell subtypes were associated with inputs to superficial layer neurons. Excitatory synaptic connectivity from superficial to deep layers dominates in local circuits (Thomson and Morris, 2002), whereas ascending interactions are, at least locally, predominantly inhibitory. However, some ascending excitation has been noted. Theta-generating layer 5 RS pyramids have ascending collaterals that

IPSPs received by these cells did not show double peaks (bottom trace). C, LTS neurons in layer 2 generated variable (1-10) spike numbers on each delta period and received weak, single maximum, compound EPSPs. $\boldsymbol{D}$, In contrast, superficial layer FS neurons generated more spikes per delta period (3-20) and had EPSP inputs that sometime displayed double peaks. Calibration: $0.1 \mathrm{mV}$ (field), $15 \mathrm{mV}$ (spike traces), $5 \mathrm{mV}$ (postsynaptic potentials), $0.5 \mathrm{~s}$. 
A L5 bursting

$\begin{array}{lllllllllll}- & - & - & - & - & - & -\cdot & -\cdots & - & - & - \\ - & - & - & \cdot & - & - & - & - & - & - & - \\ - & - & - & - & - & - & - & - & - & - & - \\ - & - & - & - & - & - & - & - & - & - & - \\ - & - & - & - & - & - & - & - & - & \cdot & -\end{array}$

L5 RS

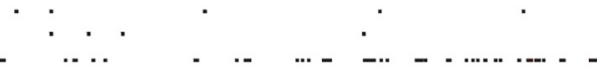

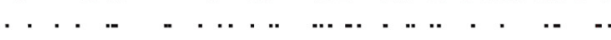

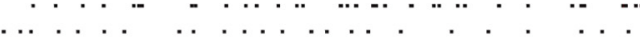

L2/3 RS

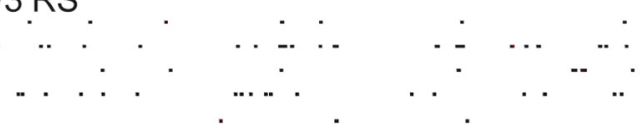

B
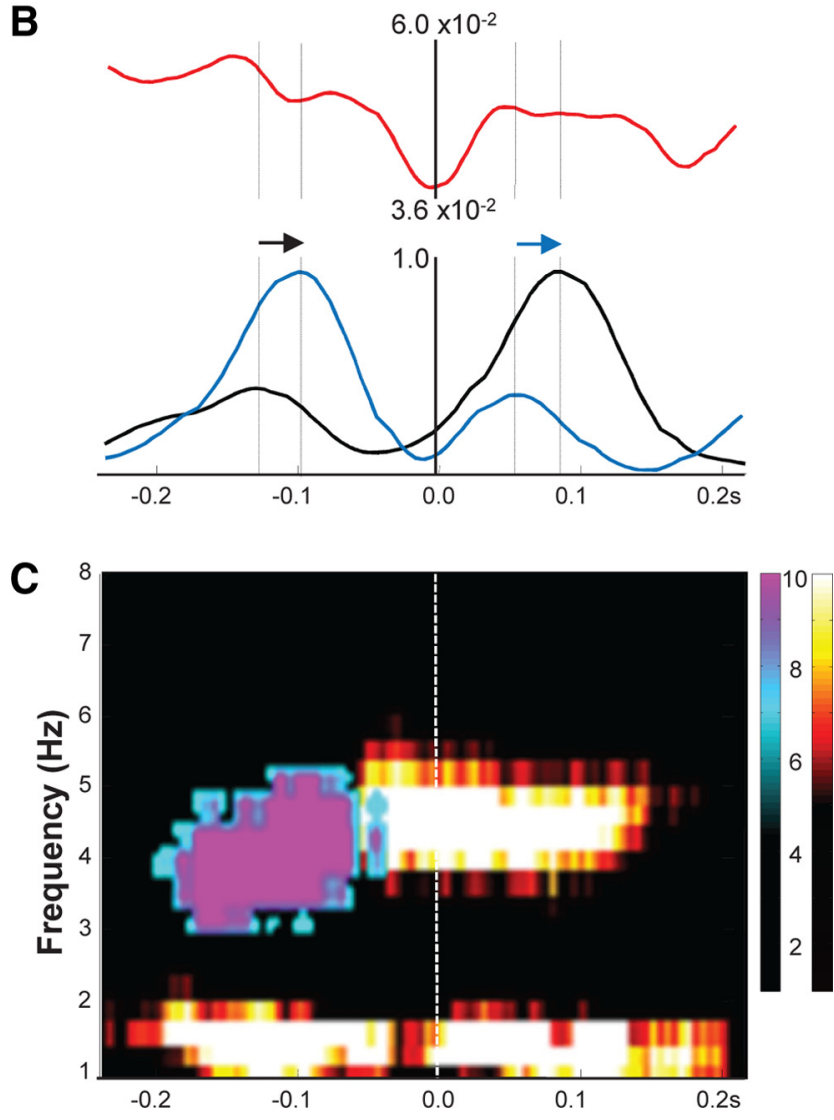

Figure 7. Relative interlaminar spike times and directed coherence show superficial layer sparse spike patterns reflected back from layer 5 . $A$, Example spike raster grams of $5 \mathrm{~s}$ data from five units in each of three classes: units in layer 5 demonstrating overt bursting phase locked to the field delta rhythm [presumed layer 5 IB neurons ( $L 5$ bursting)], units in layer 5 demonstrating single or double spikes or continuous theta-frequency spiking (presumed layer 5 RS neurons), and units in layers $2 / 3$ demonstrating sparse spiking $[<1$ spike on average per field delta period (presumed L2/3 RS neurons)]. Scale bar, $1 \mathrm{~s}$. B. Mean ( $n=5$ units per $N=5$ slices) spike-spike cross-correlograms for presumed $L 5$ RS versus $L 2 / 3$ RS neurons (red), L2/3 RS units versus $\mathrm{L} 5$ field delta rhythm (black), and $\mathrm{L} 5 \mathrm{RS}$ neuron units versus $\mathrm{L} 5$ field delta rhythm (blue). Note the temporal order of occurrence of the double peaks for the L2/3 and L5 RS units is reversed for the second compared with the first spike maxima per field delta period (arrows). $C$, Directed coherence estimates per delta period from concurrently recorded field potentials in layers 2 and $5 . \mathrm{L} 2 / 3 \rightarrow \mathrm{L} 5$ (cool color map) shows a peak in directed coherence early in the delta period at $\sim 4 \mathrm{~Hz}$. $\mathrm{L} 5 \rightarrow \mathrm{L} 2 / 3$ (hot color map) shows delta frequency directed coherence throughout the period but a maximum in the theta range later in the delta period.

stay mainly within the column, exciting layers 2 and 3 (Lefort et al., 2009). IB neurons also weakly project back up to superficial layers horizontally over many millimeters. In the present study, IB cell outputs were predominantly associated with delta- frequency epochs of fast inhibition in superficial layers, whereas RS cell outputs correlated with single or pairs of EPSPs in layer $2 / 3$. These precedents suggest a process whereby on-going sparse activity in superficial layers precipitates a delta burst in layer 5 through convergence of descending interlaminar axons (Kampa et al., 2006). If there is sufficient excitation of RS cells by IB cells to foster rhythmic (theta frequency; Fig. 5) outputs, then divergent connections back up to layers $2 / 3$ cause additional periods of excitation during the active phase of each delta period. These observations suggest an iterative switching of superficial and deep layer activity on each delta period. Thus, layer 5 may play a key role in comparing, contrasting, and combining multiple, discrete sensory representations manifest in superficial neuronal firing patters-roles suggested for delta rhythms during deep sleep (Riedner et al., 2007; Peyrache et al., 2009).

This type of switching between descending and ascending interlaminar interactions has been seen during wake state on a slower timescale and more persistently during memory tasks: coding of sensory inputs is associated with descending interlaminar communication, whereas the subsequent memory component of the task sees a switch to ascending interactions (Takeuchi et al., 2011). Sleep-associated slow rhythms in general have been proposed to be temporally discrete fragments of wakefulness (Destexhe et al., 2007). Thus, it is perhaps not surprising that brief, iterative epochs of this sensory/memory-associated communication switch are seen during delta rhythms. In addition, this pattern of activity closely matches the Helmholtz machine proposed by Hinton and colleagues as a general format for unsupervised learning (Hinton and Zemel, 1994; Hinton et al., 1995). Neural networks with laminar organization (as seen in neocortex) can converge onto a minimal generative model of patterns in given datasets if reciprocal interactions occur between layers iteratively and with alternating directionality.

Plastic changes in neuronal functional connections, formed during previous waking periods, have been proposed as "synaptic rescaling"-the restoration of a mean baseline of synaptic weights in cortex (Tononi and Cirelli, 2003, 2006). The occurrence of delta generators in associational areas and the general pattern of dominance of outputs from layer 5 from higher-order cortical areas (Rouiller et al., 1991) also suggests more subtle synaptic changes favoring the establishment of longer-range functional connections than those induced by sensory input, thus perhaps contextualizing previous experiences. However, what evidence exists to support these ideas?

Experimentally controlled activation of discrete cortical areas with TMS during waking shows altered delta power during subsequent sleep episodes (Massimini et al., 2007). Behavioral studies show that delta rhythm generation during deep sleep are associated with enhancement of declarative memory (Huber et al., 2004; Aeschbach, 2009). Evidence also exists for stimulusspecific potentiation of delta rhythms [e.g., hand vibration (Kattler et al., 1994) or whisker stimulation], and memory trace reactivation during sleep for spike timing sequences in prefrontal cortex is associated with "learned rules" (Peyrache et al., 2009). Functional clustering algorithms, applied to electrophysiological signals during deep sleep, also show state-dependent clustering consistent with known processes involved in memory consolidation (Feldt et al., 2009), and evidence exists for sleep-dependent enhancement of visual cortex remodeling (ocular dominance plasticity; Aton et al., 2009), a process requiring NMDAR activation. In addition, neuromodulatory substances that promote delta rhythm generation are also implicated in AMPAR trafficking (Baracchi and Opp, 2008; Cingolani et al., 2008). 
The type of plasticity seen during deep sleep appears to be dominated by long-term depression. Computational models predict that, as delta rhythms decline during sleep, so does overall cortical synaptic strength (Riedner et al., 2007) and GluR1 receptor phosphorylation levels are potentiated during wakefulness and depressed after sleep (Vyazovskiy et al., 2008). The present data point to a process whereby the most salient features of sensory information (coded as the largest previous increases in synaptic weights) facilitate reciprocal interlaminar interactions and are thus represented at theta frequencies and "spared" as a cortical population code. However, codes for events of lesser salience fail to activate reciprocal interlaminar interactions and may therefore be deleted through synaptic depression at delta frequencies: the dominance of delta-frequency synaptic inhibition by ascending inputs from IB neurons to superficial layers may serve to depotentiate local layer $2 / 3$ activity unless it is followed by additional periods of excitation at theta frequencies. In general, patterned theta-frequency activity has been shown to facilitate synaptic potentiation (Larson et al., 1986), whereas in contrast, delta-frequency activity facilitates depression (Staubli and Lynch, 1990). The coexpression of these two frequencies during deep sleep and in the present model suggests a balance between upregulation and downregulation of synaptic strength. However, the neuromodulatory state required to see cortical delta rhythms shifts this balance toward depression: dopamine $\mathrm{D}_{1}$ receptor activation impairs long-term depression and enhances spike-timing-dependent long-term potentiation (Xu and Yao, 2010). Reduction in $\mathrm{D}_{1}$ tone (with SCH23390) was a critical component of the in vitro model used in the present study.

When dopamine levels are high during wakefulness and thus synaptic plasticity facilitated, a lower-amplitude delta rhythm (compared with the sleep state) still dominates the EEG spectrum. It is also seen to nest theta rhythms (Lakatos et al., 2005) and the processing of sensory information (Lakatos et al., 2008) in which it is seen to be precisely phase reset by entrainment to sensory input. This results in response gain enhancement and reaction time increases (Lakatos et al., 2008). Such a process is seen predominantly when there is a pattern of sensory input to entrain to. Without this, the lower frequency "carrier wave" becomes detrimental to cortical function and is actively suppressed in favor of a state of near-continuous vigilance manifest as continuous high-frequency rhythms (Schroeder and Lakatos, 2009). Therefore, it may be the case that dominant delta rhythms in NREM3 and NREM4 may subserve a similar function but with internally held codes for sensory information acquired previously and with a neuromodulator state favoring depression, rather than potentiation, of synaptic strength.

In summary, the present data uncover a pattern of cortical dynamics that may underlie an unsupervised synaptic rescaling process akin to the Helmholtz machine theory proposed previously. The complexity of the interlaminar interactions observed suggests the capacity for nesting of multiple higher frequencies in the delta rhythm and constitutes a substrate upon which to investigate the nature and loci of sleep-associated synaptic plasticity and related pathologies.

\section{References}

Aeschbach D (2009) Slow waves and learning: beyond correlations. Sleep 32:1253-1254. Medline

Amzica F, Steriade M (1998) Electrophysiological correlates of sleep delta waves. Electroencephalogr Clin Neurophysiol 107:69-83. CrossRef Medline

Amzica F, Nuñez A, Steriade M (1992) Delta frequency (1-4 Hz) oscilla- tions of perigeniculate thalamic neurons and their modulation by light. Neuroscience 51:285-294. CrossRef Medline

Armstrong-James M, Fox K (1988) Evidence for a specific role for cortical NMDA receptors in slow-wave sleep. Brain Res 451:189-196. CrossRef Medline

Aton SJ, Seibt J, Dumoulin M, Jha SK, Steinmetz N, Coleman T, Naidoo N, Frank MG (2009) Mechanisms of sleep-dependent consolidation of cortical plasticity. Neuron 61:454-466. CrossRef Medline

Baracchi F, Opp MR (2008) Sleep-wake behavior and responses to sleep deprivation of mice lacking both interleukin-1 beta receptor 1 and tumor necrosis factor-alpha receptor 1. Brain Behav Immun 22:982-993. CrossRef Medline

Beltramo R, D'Urso G, Dal Maschio M, Farisello P, Bovetti S, Clovis Y, Lassi G, Tucci V, De Pietri Tonelli D, Fellin T (2013) Layer-specific excitatory circuits differentially control recurrent network dynamics in the neocortex. Nat Neurosci 16:227-234. CrossRef Medline

Borbély AA, Baumann F, Brandeis D, Strauch I, Lehmann D (1981) Sleep deprivation: effect on sleep stages and EEG power density in man. Electroencephalogr Clin Neurophysiol 51:483-495. Medline

Campbell IG, Feinberg I (2009) Longitudinal trajectories of non-rapid eye movement delta and theta EEG as indicators of adolescent brain maturation. Proc Natl Acad Sci U S A 106:5177-5180. CrossRef Medline

Cingolani LA, Thalhammer A, Yu LM, Catalano M, Ramos T, Colicos MA, Goda Y (2008) Activity-dependent regulation of synaptic AMPA receptor composition and abundance by beta3 integrins. Neuron 58:749-762. CrossRef Medline

Compte A, Sanchez-Vives MV, McCormick DA, Wang XJ (2003) Cellular and network mechanisms of slow oscillatory activity $(<1 \mathrm{~Hz})$ and wave propagations in a cortical network model. J Neurophysiol 89:2707-2725. CrossRef Medline

Crunelli V, Hughes SW (2010) The slow $(<1 \mathrm{~Hz})$ rhythm of non-REM sleep: a dialogue between three cardinal oscillators. Nat Neurosci 13: 9-17. CrossRef Medline

Csercsa R, Dombovári B, Fabó D, Wittner L, Eross L, Entz L, Sólyom A, Rásonyi G, Szucs A, Kelemen A, Jakus R, Juhos V, Grand L, Magony A, Halász P, Freund TF, Maglóczky Z, Cash SS, Papp L, Karmos G, Halgren E, Ulbert I (2010) Laminar analysis of slow wave activity in humans. Brain 13:2814-2829. CrossRef Medline

Cui J, Xu L, Bressler SL, Ding M, Liang H (2008) BSMART: a Matlab/C toolbox for analysis of multichannel neural time series. Neural Netw 21: 1094-1104. CrossRef Medline

Dayan P, Hinton GE, Neal RM, Zemel RS (1995) The Helmholtz machine. Neural Comput 7:889-904. CrossRef Medline

De Gennaro L, Fratello F, Marzano C, Moroni F, Curcio G, Tempesta D, Pellicciari MC, Pirulli C, Ferrara M, Rossini PM (2008) Cortical plasticity induced by transcranial magnetic stimulation during wakefulness affects electroencephalogram activity during sleep. PLoS One 3:e2483. CrossRef Medline

Destexhe A, Hughes SW, Rudolph M, Crunelli V (2007) Are corticothalamic "up" states fragments of wakefulness? Trends Neurosci 30:334-342. CrossRef Medline

Feldt S, Waddell J, Hetrick VL, Berke JD, Zochowski M (2009) Functional clustering algorithm for the analysis of dynamic network data. Phys Rev E Stat Nonlin Soft Matter Phys 79:056104. Medline

Fell J, Elfadil H, Röschke J, Burr W, Klaver P, Elger CE, Fernández G (2002) Human scalp recorded sigma activity is modulated by slow EEG oscillations during deep sleep. Int J Neurosci 112:893-900. Medline

Franco-Pérez J, Paz C (2009) Quinine, a selective gap junction blocker, decreases REM sleep in rats. Pharmacol Biochem Behav 94:250-254. CrossRef Medline

Franken P, Dijk DJ, Tobler I, Borbély AA (1991) Sleep deprivation in rats: effects on EEG power spectra, vigilance states, and cortical temperature. Am J Physiol 261:R198-R208. Medline

Haider B, Duque A, Hasenstaub AR, McCormick DA (2006) Neocortical network activity in vivo is generated through a dynamic balance of excitation and inhibition. J Neurosci 26:4535-4545. CrossRef Medline

Hasenstaub A, Shu Y, Haider B, Kraushaar U, Duque A, McCormick DA (2005) Inhibitory postsynaptic potentials carry synchronized frequency information in active cortical networks. Neuron 47:423-435. CrossRef Medline

Hinton GE, Zemel RS (1994) Autoencoders, minimum description length and Helmholtz free energy. In: Advances in neural information process- 
ing systems 6 (Cowan JD, Tesauro G, Alspector J, eds), pp 3-10. San Mateo, CA: Kaufmann.

Hinton GE, Dayan P, Frey BJ, Neal RM (1995) The "wake-sleep" algorithm for unsupervised neural networks. Science 268:1158-1161. CrossRef Medline

Huber R, Ghilardi MF, Massimini M, Tononi G (2004) Local sleep and learning. Nature 430:78-81. CrossRef Medline

Hughes SW, Cope DW, Tóth TI, Williams SR, Crunelli V (1999) All thalamocortical neurones possess a T-type $\mathrm{Ca}^{2+}$ "window" current that enables the expression of bistability-mediated activities. J Physiol 517: 805-815. CrossRef Medline

Hughes SW, Cope DW, Blethyn KL, Crunelli V (2002) Cellular mechanisms of the slow $(<1 \mathrm{~Hz})$ oscillation in thalamocortical neurons in vitro. Neuron 33:947-958. CrossRef Medline

Ioannides AA, Kostopoulos GK, Liu L, Fenwick PB (2009) MEG identifies dorsal medial brain activations during sleep. Neuroimage 44:455-468. CrossRef Medline

Kampa BM, Letzkus JJ, Stuart GJ (2006) Cortical feed-forward networks for binding different streams of sensory information. Nat Neurosci 9:14721473. CrossRef Medline

Kattler H, Dijk DJ, Borbély AA (1994) Effect of unilateral somatosensory stimulation prior to sleep on the sleep EEG in humans. J Sleep Res 3:159164. CrossRef Medline

Krueger JM, Obál F (1993) A neuronal group theory of sleep function. J Sleep Res 2:63-69. CrossRef Medline

Lakatos P, Shah AS, Knuth KH, Ulbert I, Karmos G, Schroeder CE (2005) An oscillatory hierarchy controlling neuronal excitability and stimulus processing in the auditory cortex. J Neurophysiol 94:1904-1911. CrossRef Medline

Lakatos P, Karmos G, Mehta AD, Ulbert I, Schroeder CE (2008) Entrainment of neuronal oscillations as a mechanism of attentional selection. Science 320:110-113. CrossRef Medline

Larson J, Wong D, Lynch G (1986) Patterned stimulation at the theta frequency is optimal for the induction of hippocampal long-term potentiation. Brain 368:347-350. CrossRef Medline

Lefort S, Tomm C, Floyd Sarria JC, Petersen CC (2009) The excitatory neuronal network of the $\mathrm{C} 2$ barrel column in mouse primary somatosensory cortex. Neuron 61:301-316. CrossRef Medline

Massimini M, Ferrarelli F, Esser SK, Riedner BA, Huber R, Murphy M, Peterson MJ, Tononi G (2007) Triggering sleep slow waves by transcranial magnetic stimulation. Proc Natl Acad Sci U S A 104:8496-8501. CrossRef Medline

Mercer A, Bannister AP, Thomson AM (2006) Electrical coupling between pyramidal cells in adult cortical regions. Brain Cell Biol 35:13-27. Medline

Mormann F, Osterhage H, Andrzejak RG, Weber B, Fernández G, Fell J, Elger CE, Lehnertz K (2008) Independent delta/theta rhythms in the human hippocampus and entorhinal cortex. Front Hum Neurosci 2:3. CrossRef Medline

Oláh S, Füle M, Komlósi G, Varga C, Báldi R, Barzó P, Tamás G (2009) Regulation of cortical microcircuits by unitary GABA-mediated volume transmission. Nature 461:1278-1281. CrossRef Medline

Peyrache A, Khamassi M, Benchenane K, Wiener SI, Battaglia FP (2009)
Replay of rule-learning related neural patterns in the prefrontal cortex during sleep. Nat Neurosci 12:919-926. CrossRef Medline

Pirchio M, Turner JP, Williams SR, Asprodini E, Crunelli V (1997) Postnatal development of membrane properties and delta oscillations in thalamocortical neurons of the cat dorsal lateral geniculate nucleus. J Neurosci 17:5428-5444. Medline

Riedner BA, Vyazovskiy VV, Huber R, Massimini M, Esser S, Murphy M, Tononi G (2007) Sleep homeostasis and cortical synchronization: III. A high-density EEG study of sleep slow waves in humans. Sleep 30:16431657. Medline

Rouiller EM, Simm GM, Villa AE, de Ribaupierre Y, de Ribaupierre F (1991) Auditory corticocortical interconnections in the cat: evidence for parallel and hierarchical arrangement of the auditory cortical areas. Exp Brain Res 86:483-505. Medline

Schroeder CE, Lakatos P (2009) The gamma oscillation: master or slave? Brain Topogr 22:24-26. CrossRef Medline

Shu Y, Hasenstaub A, McCormick DA (2003) Turning on and off recurrent balanced cortical activity. Nature 423:288-293. CrossRef Medline

Staubli U, Lynch G (1990) Stable depression of potentiated synaptic responses in the hippocampus with 1-5 Hz stimulation. Brain Res 513:113118. CrossRef Medline

Takeuchi D, Hirabayashi T, Tamura K, Miyashita Y (2011) Reversal of interlaminar signal between sensory and memory processing in monkey temporal cortex. Science 331:1443-1447. CrossRef Medline

Thomson AM, Morris OT (2002) Selectivity in the inter-laminar connections made by neocortical neurones. J Neurocytol 31:239-246. CrossRef Medline

Tononi G, Cirelli C (2003) Sleep and synaptic homeostasis: a hypothesis. Brain Res Bull 62:143-150. CrossRef Medline

Tononi G, Cirelli C (2006) Sleep function and synaptic homeostasis. Sleep Med Rev 10:49-62. CrossRef Medline

Traub RD, Jefferys JG, Miles R, Whittington MA, Tóth K (1994) A branching dendritic model of a rodent CA3 pyramidal neurone. J Physiol 481: 79-95. Medline

Traub RD, Contreras D, Cunningham MO, Murray H, Le Beau FE, Roopun A, Bibbig A, Wilent WB, Higley MJ, Whittington MA (2005) Singlecolumn thalamocortical network model exhibiting gamma oscillations, sleep spindles and epileptogenic bursts. J Neurophysiol 93:2194-2232. Medline

Van Dongen HP, Caldwell JA Jr, Caldwell JL (2006) Investigating systematic individual differences in sleep-deprived performance on a high-fidelity flight simulator. Behav Res Methods 38:333-343. Medline

Vassalli A, Dijk DJ (2009) Sleep function: current questions and new approaches. Eur J Neurosci 29:1830-1841. CrossRef Medline

Vyazovskiy VV, Cirelli C, Tononi G, Tobler I (2008) Cortical metabolic rates as measured by 2-deoxyglucose-uptake are increased after waking and decreased after sleep in mice. Brain Res Bull 75:591-597. CrossRef Medline

Vyazovskiy VV, Olcese U, Hanlon EC, Nir Y, Cirelli C, Tononi G (2011) Local sleep in awake rats. Nature 472:443-447. CrossRef Medline

Xu TX, Yao WD (2010) D1 and D2 dopamine receptors in separate circuits cooperate to drive associative long-term potentiation in the prefrontal cortex. Proc Natl Acad Sci U S A 107:16366-16371. CrossRef Medline 